\title{
Aus den Lehrjahren von Walter Rogowski.
}

Rogowski gehörte zu den frühesten Hörern meiner Vorlesungen über technische Mechanik in Aachen. Er fiel mir durch sein Interesse und intelligentes Fragen auf. Das Vorexamen bestand er natürlich glänzend. Hier aber erwuchs ihm ein Konkurtent oder, sagen wir lieber, ein gleichwertiger Partner in Peter DeBye. Dieser hatte sich mit einer gewissen Sprödigkeit und Befangenheit, die dem noch sehr jugendlichen Maastrichter wohl anstand, bisher von Fragen und persönlicher Annäherung zurückgehalten. Als ich aber merkte, daß RoGowski und DeBye miteinander befreundet waren, zog ich sie gemeinsam an mich heran. Sie studierten zusammen, weit über den Lehrplan der Technischen Hochschule hinausgreifend, Werke der theoretischen Physik, z. B. die Optik von Drude und wohl gar den MAXWELlschen Treatise. Wie oft saßen die wissenschaftlichen Zwillinge bei mir zu Hause, um Fragen zu stellen und Anregungen zu empfangen!

Im Jahre 1905 wurde mein mathematischer Kollege $H$. von MANGOLDT als Rektor an die neu gegründete Danziger Hochschule berufen. Er suchte einen von ihm mitzunehmenden Assistenten und fragte mich um Rat. Ich nannte ihm in einem Atem Rogowski und DEBYE, die auch ihm natürlich als besonders tüchtig aufgefallen waren. Daß er RoGowskI wählte, war fast ein Zufall; den Ausschlag gab wohl der Umstand, daß RoGowski aus dem Osten, DeBye aus Holland stammte. So kam es, daß Rogowski seine Studien in Danzig vollendete und dort 1907 promovierte. So kam es weiter, daß ich, als ich nach Ablehnung eines Rufs an die Berliner Bergakademie die Möglichkeit hatte, einen Assistenten anzustellen, DEBYE dazu machte. Hätte v. MANGOLDT sich umgekehrt entschieden, so wäre es Rogowski geworden.

Diese alten Erinnerungen mögen zeigen, wie sehr Rogowski mit seinen Interessen und seiner wissenschaftlichen Entwicklung dem physikalisch-mathematischen Mutterboden verhaftet war. Diesem ist er auch in der Folge treu geblieben, zuerst an der Physikalisch-Technischen Reichsanstalt angestellt, dann an der Universität Jena als Professor für technische Physik. Auch in Aachen waren es physikalische Probleme großen Stils, der Kathodenstrahloszillograph und die Frage der Gasentladungen, auf die er seine Forschung und die Arbeit seiner Schule richtete.

Unser persönlicher Zusammenhang blieb erhalten. Ich konnte der Einweihung seines Institutsneubaues, an der auch der damalige Kultusminister BECKER teilnahm, beiwohnen. Ich traf ihn auf Reisen zusammen mit seiner Schwester am schönen Gardasee. Er brachte mir mit gerechtem Stolz die ersten zehn Jahrgänge seines Archivs als Geschenk in mein Münchner Irstitut. Ich schickte ihm meinen ältesten Sohn als Studenten und später als Assistenten und Promoventen nach Aachen. Mit seiner lieben Frau verbanden mich landsmännische Beziehungen aus dem äußersten Norden unseres Vaterlandes.

Über die Arbeiten seines Institutes in der Zeit seiner Reife werden seine Schüler berichten. Mir lag es ob, die Anfänge seiner wissenschaftlichen Laufbahn zu beleuchten. Daß dabei so viel Persönliches mitschwang, möge bezeugen, wie tief alle Mitarbeiter dieses Erinnerungsheftes den Verlust des viel zu früh Abberufenen mitfühlen.

A. SOMMERFELD. 